\title{
Dynamic release and transformation of metallic copper colloids in flooded paddy soil: Role of soil reducible sulfate and temperature
}

\author{
Hang Xu $\mathrm{Xu}^{\mathrm{a}}$, Bing Xia ${ }^{\mathrm{b}}$, Erkai He ${ }^{\mathrm{a}, \mathrm{b}, *}$, Rongliang Qiu ${ }^{\mathrm{b}}$, Willie J.G.M. Peijnenburg ${ }^{\mathrm{c}, \mathrm{d}}$, Hao Qiu ${ }^{\mathrm{a}, \mathrm{b}, *}$, \\ Ling Zhao ${ }^{\mathrm{a}}$, Xiaoyun $\mathrm{Xu}^{\mathrm{a}}$, Xinde $\mathrm{Cao}^{\mathrm{a}}$ \\ ${ }^{a}$ School of Environmental Science and Engineering, Shanghai Jiao Tong University, Shanghai, 200240, China \\ ${ }^{\mathrm{b}}$ Guangdong Provincial Key Laboratory of Environmental Pollution Control and Remediation Technology, Sun Yat-sen University, Guangzhou, 510275, China \\ ${ }^{\mathrm{c}}$ Institute of Environmental Sciences, Leiden University, Leiden, 2333CC, the Netherlands \\ ${ }^{\mathrm{d}}$ National Institute of Public Health and the Environment, Center for the Safety of Substances and Products, Bilthoven, 3720 BA, The Netherlands
}

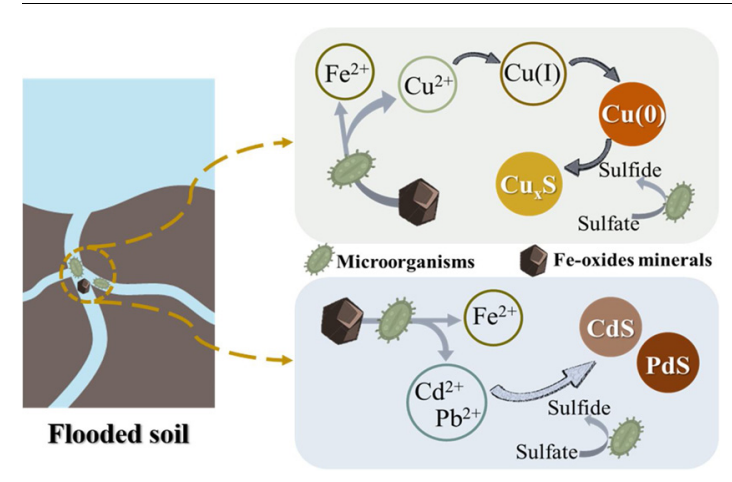

A R T I C L E I N F O

\section{Editor: T. Meiping}

Keywords:

Metal colloid

Release

Transformation

Reducible sulfate

Temperature

\begin{abstract}
A B S T R A C T
Mobile metal $\mathrm{Cu}$ colloids can be formed in periodically flooded paddy soils, potentially aggravating the risks to rice cultivated in these soils. Here, we investigated the formation and fate of Cu colloids in flooded soil as influenced by soil reducible sulfate and temperature. In microcosms with different initial sulfate availability (1.30, 5.34, or $7.38 \mathrm{mmol} / \mathrm{kg}$ ), we found the treatments with higher sulfate concentrations showed the greater and faster release of metal colloids. Sulfate reduction resulted in the transformation of copper in the colloids from $\mathrm{Cu}(0)$ to $\mathrm{Cu}_{\mathrm{x}} \mathrm{S}$, and the percentage of $\mathrm{Cu}_{\mathrm{x}} \mathrm{S}$ in the colloid phase increased with increasing sulfate content according to the $\mathrm{Cu} \mathrm{K}$-edge EXAFS spectra. The batch experiments incubated at 5,25 or $35{ }^{\circ} \mathrm{C}$ proved that high temperature enhanced the microbial activity and released more $\mathrm{Cu}$ colloids during flooding. The colloid formation was delayed at low temperature but persisted longer in the soil, which led to greater particle average size because of slow growth and uniform agglomeration. Low temperature appeared to only influence the formation and growth but not the speciation of Cu colloids. Our results highlight the importance of soil reducible sulfate and temperature in mediating the dynamics of colloidal metals in flooded soil.
\end{abstract}

\footnotetext{
*Corresponding authors at: School of Environmental Science and Engineering, Shanghai Jiao Tong University, Shanghai, 200240, China.

E-mail addresses: heerk@mail.sysu.edu.cn (E. He), haoqiu@sjtu.edu.cn (H. Qiu).
} 


\section{Introduction}

Paddy soils are usually polluted by multiple heavy metals, such as $\mathrm{Cu}, \mathrm{Cd}, \mathrm{Pb}$, and $\mathrm{As}$, that cause great environmental concern about food safety and human health worldwide (Ma et al., 2008). Periodic flooding can significantly affect the bioavailability and mobility of trace metals by restricting $\mathrm{O}_{2}$ diffusion into the soil. Some investigations reported the formation of metal colloids in the flooding condition which maintained a high mobility (Xia et al., 2018). Moreover, mobile natural colloids can serve as carriers for metal contaminants and assist their transport in the environment (Won and Burns, 2018; Wang et al., 2013). Therefore, for a proper risk assessment, it requires an in-depth understanding of the formation and fate of mobile natural metal colloids in flooded soils.

The transition from aerobic to anaerobic conditions facilitates the formation and stability of natural colloids. Metal ions can be bound to natural organic matter (NOM) and be present as colloidal species. Liao et al. (2017) found that NOM-Fe colloids are formed at the anoxic-oxic interfaces by means of the complexation and coagulation. Meanwhile, soil microorganisms are considered to play important roles in the release of colloids or nanoparticles by mediating various biochemical reactions under anoxic conditions. A previous study reported that endomycorrhizal fungi assisted wetland plants to transform $\mathrm{Cu}(\mathrm{II})$ to $\mathrm{Cu}$ (0) nanoparticles at the soil-root interface (Manceau et al., 2008), while bacteria dispersed in the porewater induced the formation of $\mathrm{Cu}(0)$ colloids via biomineralization under flooded conditions (Weber et al., 2009a).

In addition to metallic colloids, various investigations also provided sufficient evidences for the release of metal sulfide colloids in flooded soils since microbial sulfate reduction can significantly influence the transformation of metal species in the environment (Weber et al., 2009a). The occurrence and extent of metal sulfidation is highly dependent on the amount of sulfate available for microbial reduction in the soil. $\mathrm{Cu}(0)$ and $\mathrm{Cu}(\mathrm{I})-\mathrm{S}_{\text {org }}$ were the predominant species at sulfate depleted conditions over the flooding period of soil, whereas in soils containing enhanced sulfate levels, $\mathrm{Cu}(0)$ was transformed into $\mathrm{Cu}-$ sulfide upon sulfate reduction (Fulda et al., 2013a). When the concentration of reducible sulfate is limited, different metal contaminants may compete with each other for the reaction with biogenic sulfide. Weber et al. (2009b) reported that $\mathrm{Cu}, \mathrm{Cd}$, and $\mathrm{Pb}$ were easily sequestered in metal sulfide phases, whereas $\mathrm{Zn}, \mathrm{Ni}$, and $\mathrm{Fe}$ were hardly. Despite the numerous studies on the dynamics of metal contaminants in their dissolved and solid state in paddy soils with various sulfate contents, there is barely any information available about the effect of sulfate availability on formation and behavior of metal colloids in porewater under flooded conditions.

The chemical speciation and fate of heavy metals in soil are dependent on a series of biogeochemical processes that are mainly mediated by soil microorganisms (Chen et al., 2019). Differences in temperature as caused by seasonal variations or climate change no doubt affect such biogeochemical reactions, thus influencing the dynamics of trace metals in paddy soil. High temperature accelerated and enhanced the microbial reductive dissolution of Fe(III) and Mn(III, IV) (oxyhydr)oxides, which could further promote the release of dissolved and colloidal trace metal in the flooded soil (Hofacker et al., 2013b). The rate and extent of microbial sulfate reduction were reported to increase upon increasing temperature in rice paddy soil (Van Bodegom and Stams, 1999). In addition, temperature could also affect the abiotic processes in the environment. For example, the reaction rate increases by $1.5-3$ times for every $10{ }^{\circ} \mathrm{C}$ increase in temperature (Brezonik, 1994). A change in temperature leads to numerous reactions that make the dynamics of metal contaminants in the environment elusive. On the one hand, reductive dissolution promotes the release of dissolved and colloidal metals, originally adsorbed onto minerals, into porewater. On the other hand, the reduction of large amounts of sulfate could in turn sequester mobile heavy metals into metal sulfide precipitation. Till now, the effects of temperature on the metal colloids dynamics in the flooded soils and associated mechanisms remain unclear.

With the hypothesis that sulfate and temperature can promote the natural colloids release and transformation, this study systematically investigated the impact of sulfate availability and temperature on the release, stability and transformation of copper colloids in flooded paddy soil. Special attention was paid to (1) monitor the dynamic release of $\mathrm{Cu}$ colloids as well as other chalcophile metals, including $\mathrm{Cd}, \mathrm{Pb}$, and $\mathrm{Zn}$, in the porewater during soil flooding to analyze the competition effect between these chalcophile metals; (2) measure the change of colloid particle sizes using dynamic light scattering (DLS) to evaluate their stability upon increasing soil reduction; (3) determine the speciation transformation of copper colloids at different sulfate content or temperature using X-ray absorption spectroscopy. The findings of this study will expand our understanding of the formation and fate of metallic $\mathrm{Cu}$ and metal sulfide colloids in flooded paddy soil, thus assisting the evaluation of the risk of trace metals for rice food safety.

\section{Material and methods}

\subsection{Soil and synthetic river water material}

A large amount of topsoil (0-10 cm depth) was collected from a rice paddy field in the northern Guangdong Province, South China (Dabaoshan, Shaoguan, China) $\left(24^{\circ} 31^{\prime} 37^{\prime \prime} \mathrm{N} ; 113^{\circ} 42^{\prime} 49^{\prime \prime} \mathrm{E}\right)$. The soil was dried and gently crushed with a pestle and sieved to a soil aggregate size of $<2 \mathrm{~mm}$. The basic physical and chemical properties of the soil were characterized and they are listed in Table S1. Synthetic river water was prepared. It was composed of $1.0 \mathrm{mM} \mathrm{CaSO}_{4}, 0.5 \mathrm{mM}$ $\mathrm{Mg}\left(\mathrm{NO}_{3}\right)_{2}$, and $1.9 \mathrm{mM} \mathrm{NaCl}$, resembling the main composition of the water alongside the soil sampling site in the Dabaoshan area (Huang et al., 2010).

\subsection{Soil incubation experiment}

Three different incubation series were investigated, in which the soil was adjusted to different amounts of sulfate using $\mathrm{CaSO}_{4}$ solution (Table S2). The soil incubation was performed similarly to our previous study (Xia et al., 2018). Briefly, microcosms (glass bottles; SCHOTT DURAN $^{\circledR}$, Germany) were equipped with a porous suction cup and connected to a Teflon shut-off valve. For each microcosm, $250 \mathrm{~g}$ soil (on air-dry basis) was allowed to equilibrate with $1000 \mathrm{~mL}$ of aerated synthetic river water by shaking the suspensions for $2 \mathrm{~h}$ under air. The suspension was centrifuged at $600 \mathrm{~g}$ for $15 \mathrm{~min}$. The soil paste that was collected after centrifugation was transferred into a microcosm and submerged with an additional amount of $250 \mathrm{~mL}$ of synthetic river water. No supplementary organic carbon was added into the soil. The series of microcosms were incubated in the dark at $25{ }^{\circ} \mathrm{C}$ using a temperature-controlled biochemical incubator (SPX-150, Zollo, China). The three incubation treatments are referred to as high sulfate treatment (HS) $\left(7.38 \pm 0.02 \mathrm{mmol} \mathrm{kg}{ }^{-1}\right)$, medium sulfate treatment (MS) $\left(5.34 \pm 0.03 \mathrm{mmol} \mathrm{kg}^{-1}\right)$ and low sulfate treatment (LS) $(1.30 \pm 0.04$ mmol $\mathrm{kg}^{-1}$ ), respectively. The soil with medium sulfate content (MS) was selected to study the impact of the factor temperature. Three temperature gradients $\left(35,20\right.$ and $\left.5{ }^{\circ} \mathrm{C}\right)$ were set for the flooding experiment. They represent the typical temperature in Summer, Spring, and Winter, respectively, in the Dabaoshan area.

\subsection{Porewater sampling and analysis}

Soil porewater was sampled by linking a suction cup to a syringe at day $1,3,5,10,15,20,25$, and 30 in a steel glovebox (pO2 $<1 \mathrm{ppm}$; Braun, Germany). A slow flow rate of $0.4 \mathrm{~mL} / \mathrm{min}$ was chosen to minimize sheer stress on soil grains near the suction cup. The $\mathrm{pH}$ was measured in a $1 \mathrm{~m} \mathrm{~L}$-aliquot with glass electrodes (ROSS Sure-Flow for $\mathrm{pH}$, Thermo, USA). The recovered sample was filtered through a 0.025 
$\mu \mathrm{m}$ cellulose nitrate membrane. To determine the concentration of colloidal metal, including $\mathrm{Cu}, \mathrm{Cd}, \mathrm{Pb}$, and $\mathrm{Zn}$, the unfiltered and 0.025 $\mu \mathrm{m}$-filtered aliquots were acidified using $0.5 \mathrm{M} \mathrm{HCl}$, then the acidified samples were measured with inductively coupled plasma optical emission spectrometry (ICP-OES, Optima 8300, Perkin Elmer, Germany). The metal concentration in the $0.025 \mu \mathrm{m}$-filtered porewater sample was referred to as the dissolved metal concentration $\left(C_{\text {dissolved }}\right)$. The colloidal metal concentration was derived from the difference between the unfiltered and $0.025 \mu \mathrm{m}$-filtered samples $\left(C_{\text {colloidal }}=\right.$ $\left.C_{\text {unfiltered }}-C_{\text {filtered }}\right)$. We defined the colloidal-dissolved boundary as $0.025 \mu \mathrm{m}$ because colloids $<25 \mathrm{~nm}$ may also be retained by fast diffusive transport to the filter membrane (Hofacker et al., 2013a). The concentration of $\mathrm{SO}_{4}{ }^{2-}$ was measured by ion chromatograph (DX500, Dionex, USA).

\subsection{Dynamic light scattering (DLS) analysis}

A photon correlation spectroscopy (Bi-90, Brookhaven Instruments, USA) was used to study the light scattering intensity of colloidal samples and the changes of colloidal particle size. The DLS data was obtained based on the intensity method. The light source was a solid-state Laser (LEXEL Laser, USA) with a wavelength of $514.5 \mathrm{~nm}$ and a power of $400 \mathrm{~mW}$. The measured fixed scattering angle was $90^{\circ}$. The rectangular covered glass sample tank (Hellma, Germany) was used to test the sample after loading the sample lid in the glove box. The solution temperature was controlled at $25{ }^{\circ} \mathrm{C}$, and the determination time was selected to be between 60 and $300 \mathrm{~s}$.

\subsection{Soil microbial activity analysis}

The microbial growth efficiency (MGE) and respiration rate were measured to determine the effect of temperature on soil microbial activity. After incubation for 7 and 14 days, a $3.6 \mathrm{mmol} / \mathrm{L}$ solution of either glucose labeled at specific sites $\left(\mathrm{U}_{-}{ }^{13} \mathrm{C}\right.$ and $1-{ }^{13} \mathrm{C}$ ) or pyruvate $\left(1-{ }^{13} \mathrm{C}\right.$ and $\left.2,3-{ }^{13} \mathrm{C}\right)$ was injected into the soil. For the three different incubation temperatures of 35,20 and $5{ }^{\circ} \mathrm{C}$, carbon dioxide in the sample bottles was measured at $60,90,120$ and $180 \mathrm{~min}$ after the start of cultivation, respectively. The ratio of glucose to pyruvate isotopes of ${ }^{13} \mathrm{CO}_{2}$ production rates was calculated and used in MGE. A second set of cultured samples was used to determine the respiratory rate, using LICOR 6262 (li-cor Biosciences, Lincoln, USA) to analyze the $\mathrm{CO}_{2}$ concentration after days 7 and 14 of incubation of soil flooding(Dijkstra et al., 2011).

\subsection{X-ray absorption spectroscopy analysis}

The speciation of colloidal $\mathrm{Cu}$ was determined using extended X-ray absorption fine structure (EXAFS) spectroscopy at the XAS beamline at the Shanghai Synchrotron Radiation Facility (SSRF, Shanghai, China). Colloid samples were collected by filtration through $0.025 \mu \mathrm{m}$ cellulose nitrate membranes. The membranes were washed using $5 \mathrm{~mL}$ deoxygenated ultrapure water and dried under $\mathrm{N}_{2}$ atmosphere. Then the colloid samples were stored and transported under $\mathrm{N}_{2}$ atmosphere and measured in the vacuum chamber. The beamline was equipped with a double crystal Si (111) monochromator, which was detuned to $65 \%$ of the maximum intensity using a software-controlled monochromator stabilization. Spectra of colloid samples were recorded in fluorescence mode using a 5-element Ge solid state detector. $\mathrm{Cu}(0)$, $\mathrm{Cu}_{\mathrm{x}} \mathrm{S}, \mathrm{Cu}(\mathrm{I})-\mathrm{Pcoc}$, and $\mathrm{Cu}$-carboxyl were chosen as reference compounds. The photon energy of the experimental spectra was calibrated using $\mathrm{Cu}(0)$ foil (K-edge at $8979 \mathrm{eV}$ ). $\mathrm{Cu}_{\mathrm{x}} \mathrm{S}$ was requested from Diamond Light Source, Didcot, UK (Pattrick et al., 1997). Cu(I)-PcoC was selected as a model for $\mathrm{Cu}(\mathrm{I})$ in trigonal coordination (Peariso et al., 2003). The mixture solution of $\mathrm{Cu}(\mathrm{II})$ and $\mathrm{Pcoc}$ protein was reduced with sodium ascorbate in an anaerobic glovebox. The sample was dialyzed to remove the reducing agent, combined with glycerol to $30 \%$, loaded into a Lucite cuvette, and frozen in liquid $\mathrm{N}_{2}$. Cu-carboxyl was prepared as $\mathrm{Cu}$ acetate aqueous solutions. The solutions were crystallized, then ground and dried in the glovebox.

The X-ray spectral data (the average of the three measurements) were normalized using the Athena software. Principal component analysis (PCA) was used to predict the main spectrum types that might be contained in the sample, and target transformation (TT) was used to identify the relevant standard substances used in linear combination fitting (LCF) of the sample spectrum. Principal component analysis and target transformation were carried out by SixPack software. The linear superposition fitting of the normalized sample EXAFS spectrum was carried out by Athena. For each sample, a set of standard substances with minimal residuals were used as possible components of the sample.

\section{Results and discussion}

\subsection{Dynamic release of metal colloids affected by initial sulfate content}

The changes in porewater $\mathrm{pH}$ and dissolved concentration of sulfate in high sulfate (HS), medium sulfate (MS) and low sulfate (LS) treatments during soil flooding are shown in Fig. 1. Porewater $\mathrm{pH}$ of the three sulfate treatments showed a similar trend of an initial fast increase (day1-15) followed by a slower increase (day 15-30). HS treatment induced a lower $\mathrm{pH}$ (approximately 4.4) but a faster rate of $\mathrm{pH}$ increase, causing the $\mathrm{pH}$ value of the three treatments to be similar from day 5 until the end of the exposures. This trend of increasing $\mathrm{pH}$ results from protons being consumed by reactions such as the reductive dissolution of Fe(III) and Mn(III, IV) (oxyhydr)oxides (Fulda et al., 2013a). The sulfate concentration started to slowly decrease at day 3 for HS, day 5 for MS, and day 10 for LS, respectively. The sulfate content decreased sharply after 15 days for HS and MS, while it steadily declined during the entire sulfate reduction period in the LS treatment. At the end of soil flooding, the low sulfate treatment was almost depleted. In contrast, the HS and MS treatments still retained the same sulfate concentration of $1.35 \mathrm{mM}$. About $28.6 \mathrm{mmol} / \mathrm{kg}$ acid-volatile

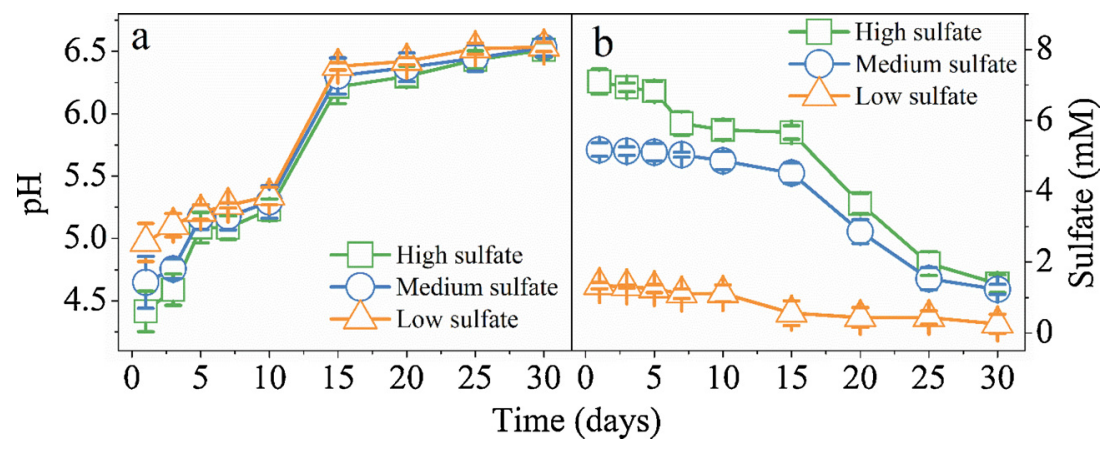

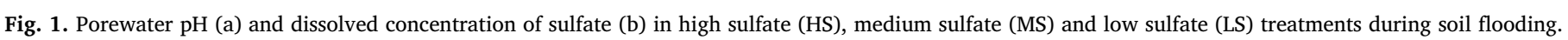




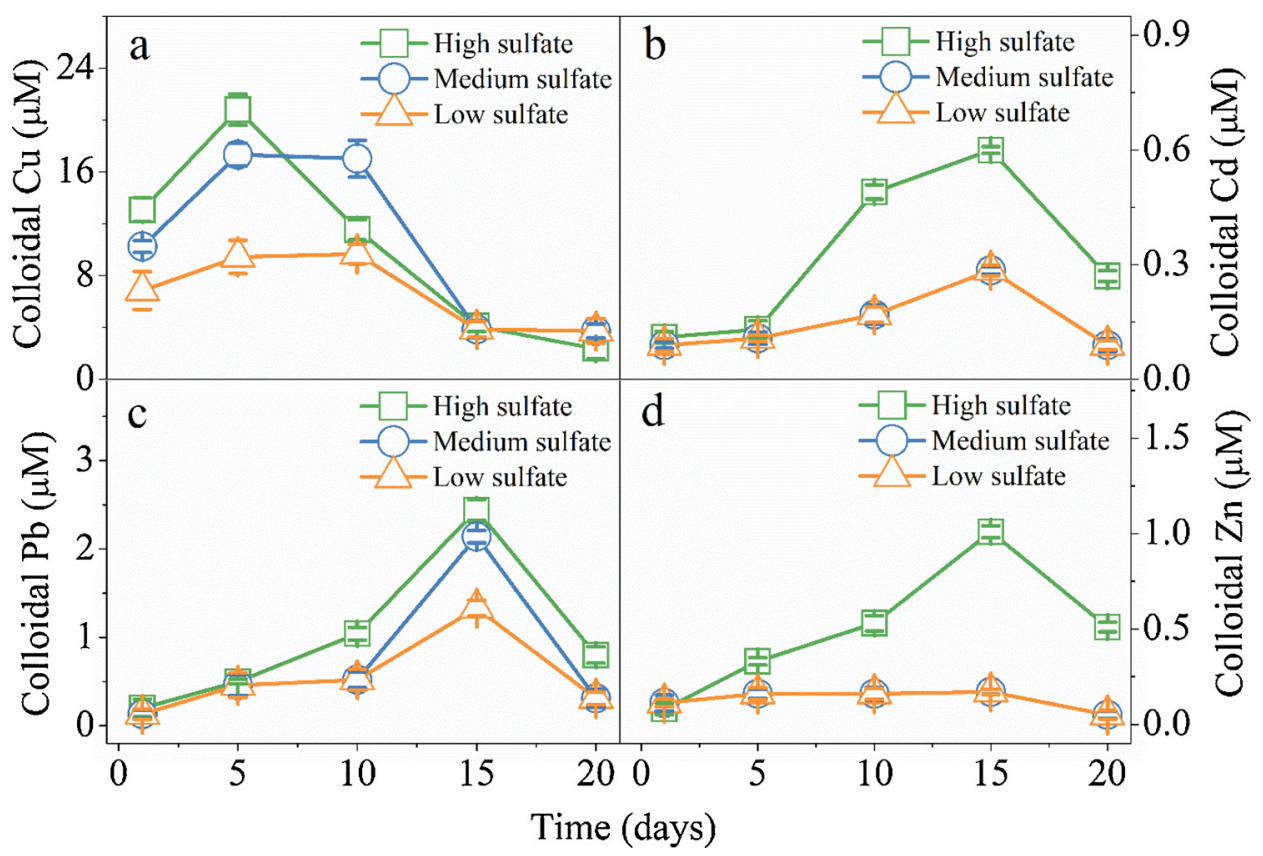

Fig. 2. Concentration of colloidal $\mathrm{Cu}(\mathrm{a}), \mathrm{Cd}(\mathrm{b}), \mathrm{Pb}(\mathrm{c})$, and $\mathrm{Zn}(\mathrm{d})$ in HS, MS and LS treatments during soil flooding.

sulfide (AVS) and $13.7 \mathrm{mmol} / \mathrm{kg}$ chromium(II)-reducible sulfur (CRS) were found after 30 days of flooding in the high sulfate treatment (Fig. $\mathrm{S} 1)$. The transformation of S species from sulfate to reduced inorganic sulfur (RIS) indicated the occurrence of microbial sulfate reduction process. The $\mathrm{S}$ species dynamics would significantly affect metal behavior in soils. Microbial anaerobic respiration of extracellular Mn-/Feoxides proceeds usually prior to sulfate. Thus, we assumed that the microbial reductive dissolution of $\mathrm{Mn}$-/Fe-oxides mainly occurred at days $1-15$, leading to the faster increase of $\mathrm{pH}$. After 15 days of flooding, microbial sulfate reduction was dominated and caused the sharply decline of sulfate content.

The concentration of colloidal $\mathrm{Cu}$ during soil flooding at different initial sulfate treatments is shown in Fig. 2a. The $\mathrm{Cu}$ colloids were formed nearly before or at the onset of microbial sulfate reduction. Colloidal $\mathrm{Cu}$ in the HS treatment reached a maximum concentration of $20.79 \mu \mathrm{M}$ after 5 days, whereas the maximum values in the MS and LS experiments occurred at days 5 and 10, respectively. The formation of metal colloids could result from soil dispersion or oxidation of artefacts (Weber et al., 2009a) and sediment resuspension (Xu et al., 2018) during flooding. The treatment with high sulfate amount showed the highest peak value of colloid $\mathrm{Cu}$ and also the greatest descent rate in $\mathrm{Cu}$ colloid concentration during the flooded period. The sulfate reduction degree was higher in the treatment with high sulfate concentration. Thus, the colloidal $\mathrm{Cu}$ formed could easily be removed from the pore water by sulfide precipitation.

The concentrations of other chalcophile metal colloids, including $\mathrm{Cd}, \mathrm{Pd}$, and $\mathrm{Zn}$, were also measured to evaluate the competition effect of dynamic release and behavior between $\mathrm{Cu}$ and other chalcophile metals. Generally, almost all metal colloid concentrations initially increased and then declined (Fig. 2b-d). However, unlike the rapid formation of colloidal $\mathrm{Cu}$ that occurred almost before the sulfate reduction, colloidal $\mathrm{Cd}, \mathrm{Pb}$ and $\mathrm{Zn}$ accumulated after the start of sulfate reduction, suggesting that these colloids may be present as metal sulfides. The concentration of these colloidal metal reached peak levels after 15 days, and then significantly decreased with the subsequent rapid reduction of sulfate. This declining trend could also result from the aggregation and precipitation of metal colloid particles. It is worth noticing that the colloidal $\mathrm{Zn}$ concentration was negligible during the entire soil flooding process at the MS and LS treatments, showing that the thermodynamic stability of these four metal sulfides are $\mathrm{Cu}>\mathrm{Cd} \sim$
$\mathrm{Pb}>\mathrm{Zn}$. The earlier formation of $\mathrm{Cu}$ colloids could be attributed to the lowest solubility product $\left(\log \mathrm{K}_{\mathrm{sp}}{ }^{\circ}\right)$ of all metal sulfide minerals in the present study $\left(\operatorname{logKsp}{ }^{\circ}(\mathrm{Cu})=-22.3, \operatorname{logKsp}{ }^{\circ}(\mathrm{Cd})=-14.4, \operatorname{logKsp}{ }^{\circ}\right.$ $\left.(\mathrm{Pb})=-14.0, \operatorname{logKsp^{\circ }}(\mathrm{Zn})=-11.5\right)$. This can also explain the negligible release of $\mathrm{Zn}$ colloids compared with the other chalcophile metals in the MS and LS treatments. Overall, the results obviously indicated that the formation of Cu colloids in the soil flooding experiment occurred before or at the onset of the sulfate reduction, whereas the formation of colloidal $\mathrm{Cd}, \mathrm{Pb}$ and $\mathrm{Zn}$ proceeded during all sulfate reduction stages. Previous studies also reported various heavy metals showed complex interactions of dynamic release into colloid phase. For example, colloidal $\mathrm{Cd}$ and $\mathrm{Pb}$ are formed later than colloidal $\mathrm{Cu}$ (Hofacker et al., 2013b), whereas Hg could be incorporated into metallic $\mathrm{Cu}$ and metal sulfide nanoparticles in flooding soils (Hofacker et al., 2013a).

In addition, the colloid mass increased to peak values of 31.4-60.4 $\mu \mathrm{g}$ in $10 \mathrm{~mL}$ sampled porewater after 15 days flooding and then decreased sharply in the three sulfate treatments (Fig. S2). This indicated that slow sulfate reduction might promote the colloid formation, whereas the rapid sulfate reduction might sequestrate the metal colloids as soil precipitates and decrease the colloid mass. The peak concentrations of metal colloids were significantly greater in the high sulfate treatment than in the medium and low sulfate treatments. The good linear relation between the sulfate amount and maximum colloid concentration $\left(R^{2}=0.91\right)$ (Fig. S3) suggested that the metal colloid release was coupled with the amount of sulfate in the flooded soil.

\subsection{Dynamic release of metal colloids as affected by temperature}

Fig. 3a shows the effect of incubation temperature on the dynamics of the colloidal $\mathrm{Cu}$ concentration during soil flooding. A pronounced peak of colloidal $\mathrm{Cu}$ concentration reached $\sim 20 \mu \mathrm{M}$ at $35{ }^{\circ} \mathrm{C}$ and $\sim 15$ $\mu \mathrm{M}$ at $20^{\circ} \mathrm{C}$ after 5 days, respectively. Then, a rapidly decreasing trend was observed from day 5 to day 30 due to the ongoing sulfate reduction. In the treatment at $5^{\circ} \mathrm{C}$, colloidal $\mathrm{Cu}$ was hardly produced in the first 10 days of incubation. This result indicated that the low temperature inhibited or delayed the initiation of colloid formation. After 25 days of soil flooding, the colloidal $\mathrm{Cu}$ concentration reached a peak value of $\sim 7 \mu \mathrm{M}$. Compared with the peak concentration of colloidal $\mathrm{Cu}$ at different temperature treatments, results showed that the release of 

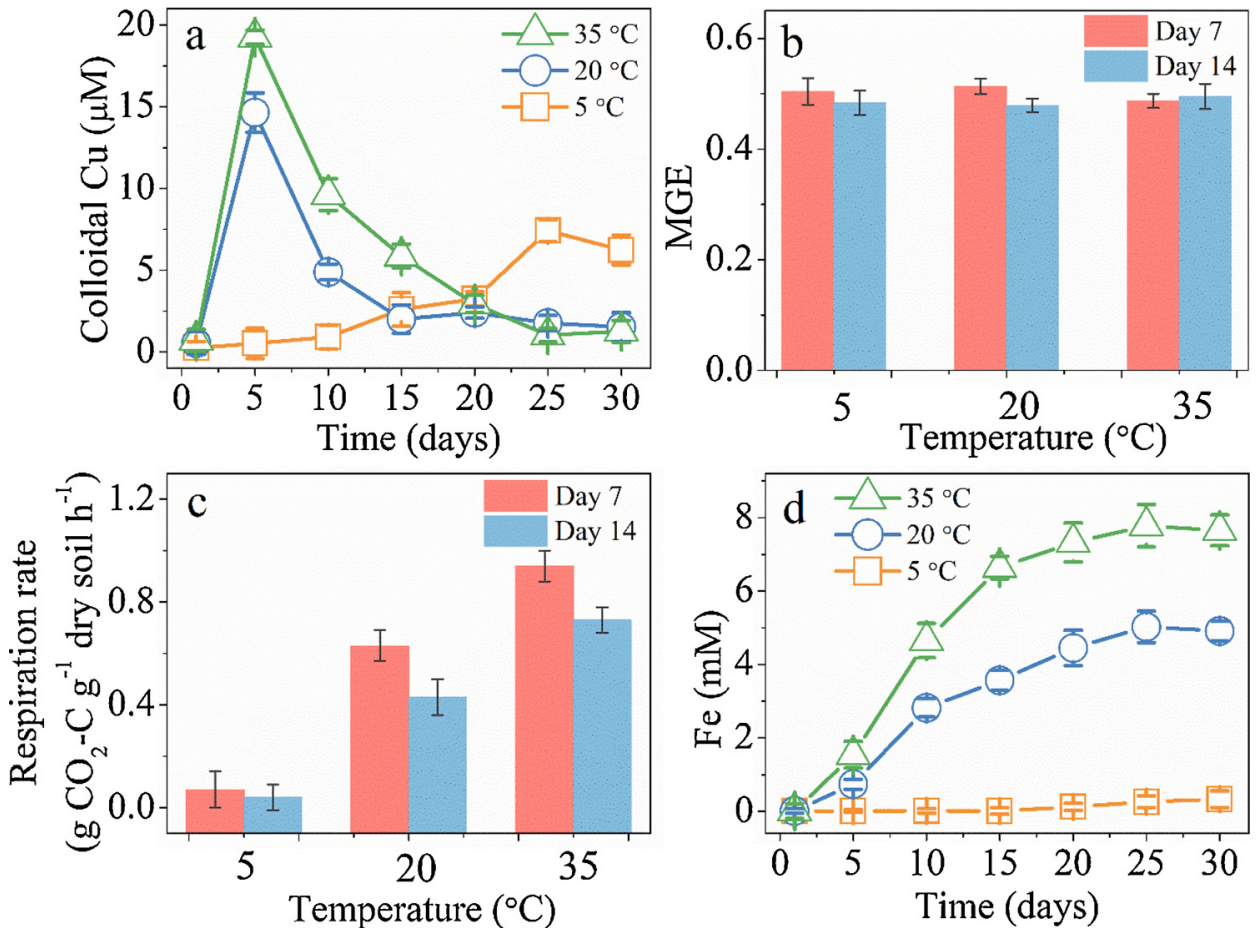

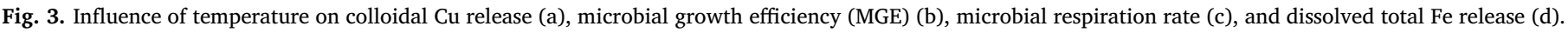

colloidal $\mathrm{Cu}$ could be promote with the increase of temperature in this study. This phenomenon can be easily understood because temperature plays a rather important role for many biogeochemical reactions, such as microbial sulfate and Fe reduction which is coupled with the environmental behavior of metal colloids (Hofacker et al., 2013b).

Investigations of response mechanisms of microorganisms to soil warming have basically focused on microbial community growth and respiration (Rousk et al., 2012; Sinsabaugh et al., 2016; Bradford, 2013). Therefore, we measured microbial growth efficiency (MGE) and respiration rate at day 7 and 14 in the different temperature treatments. The result obtained showed that MGE was nearly unchanged with the increase of temperature, indicating it was not sensitive to temperature (Fig. 3b). Hagerty et al. (2014) also found that MGE was unchanged with increase of temperature. The authors proposed that higher maintenance cost for growth at elevated temperature could be avoided through changing active microbial community hence maintaining a constant MGE.

While MGE remains stable during temperature changes, the microbial respiration rate was significantly enhanced with increasing temperature (Fig. 3c). The increased respiration rate but stable MGE indicated that temperature intensified microbial $\mathrm{C}$ metabolism through faster $C$ depletion because of the raised generation of new microbial biomass (Hagerty et al., 2014). Hofacker et al. (2013b) reported that warmer temperature led to not only greater microbial activity but also greater availability of low molecular weight organic acids. The elevated microbial activity provided a proper explanation for the faster and higher release of colloidal $\mathrm{Cu}$ at higher temperature.

The effect of temperature on microbial activity could inevitably influence reductive dissolution of Fe(III) (oxyhydr)oxides that largely control the release and mobilization of heavy metal in paddy soil system (Wang et al., 2019). Fig. 3d shows the dynamics of the dissolved total $\mathrm{Fe}$ concentration in porewater at different temperatures during soil flooding. Dissolved Fe was released immediately at $35{ }^{\circ} \mathrm{C}$ and $20{ }^{\circ} \mathrm{C}$ accompanied by the release of metal pollutants, thus promoting the formation of metal colloid in the initial period of flooding. There are two possible reasons for trace metal release: 1) the reductive dissolution of Fe oxides releases metal pollutants that were previously bound to the
Fe oxides (Davranche and Bollinger, 2000); 2) the dissolved Fe competes with trace metals for absorption sites on organic matter and mineral surfaces (Grybos et al., 2007). In the treatment of $5{ }^{\circ} \mathrm{C}$, the released $\mathrm{Fe}$ was negligible even after 15 days of incubation, then started to slowly increase. The slower and lower reductive dissolution of $\mathrm{Fe}$ oxides at $5{ }^{\circ} \mathrm{C}$ resulted in a similar trend of colloidal $\mathrm{Cu}$ concentration compared with the treatments of $20{ }^{\circ} \mathrm{C}$ and $35{ }^{\circ} \mathrm{C}$. The formation of colloidal $\mathrm{Cu}$ was lower at the low temperature treatment but lasted longer in the porewater. Therefore, dynamic release of colloidal $\mathrm{Cu}$ was largely affected by temperature and is coupled with microbial Fe reduction. The metal colloids released earlier and much more at higher temperature, whereas low temperature led to increased persistence of mobile metal colloids in porewater.

\subsection{Dynamics of metal colloids stability}

Once metal colloids are released into the porewater, their stability can influence their mobilization and bioavailability to a large extent (Wagner et al., 2014). Thus, we measured the change of the average size and light scattering intensity of the colloids using dynamic light scattering technique. Fig. 4 shows the colloidal size and their scattering light intensity at high sulfate, medium sulfate and low sulfate treatments. The change of particle size showed a similar trend despite a different initial sulfate content. Specifically, the colloidal particle size was almost stable $(60-70 \mathrm{~nm})$ from the 1 st to 10 th day. With the progress of soil reduction, the average colloidal particle size of all treatments increased by almost $40 \%$ on the day 15 , and reached the maximum particle size $(\sim 100 \mathrm{~nm})$ on the day 20 . The polydispersity index (PDI) values of all the colloidal samples were between $0.064-0.312$ (Table S3). The particles size in the LS treatment was slightly greater after 20 days of incubation compared to the cases of MS and HS treatments. This phenomenon might be caused by more uniform agglomeration that resulted from lower oversaturation because of lower sulfate reduction (Banfield and Zhang, 2001). The light scattering intensity of the three treatments increased to its maximum value after 5 days and then decreased rapidly (Fig. 4b). The peak value of light scattering intensity was slightly higher at high sulfate $(89.7 \mathrm{kcps})$ than 


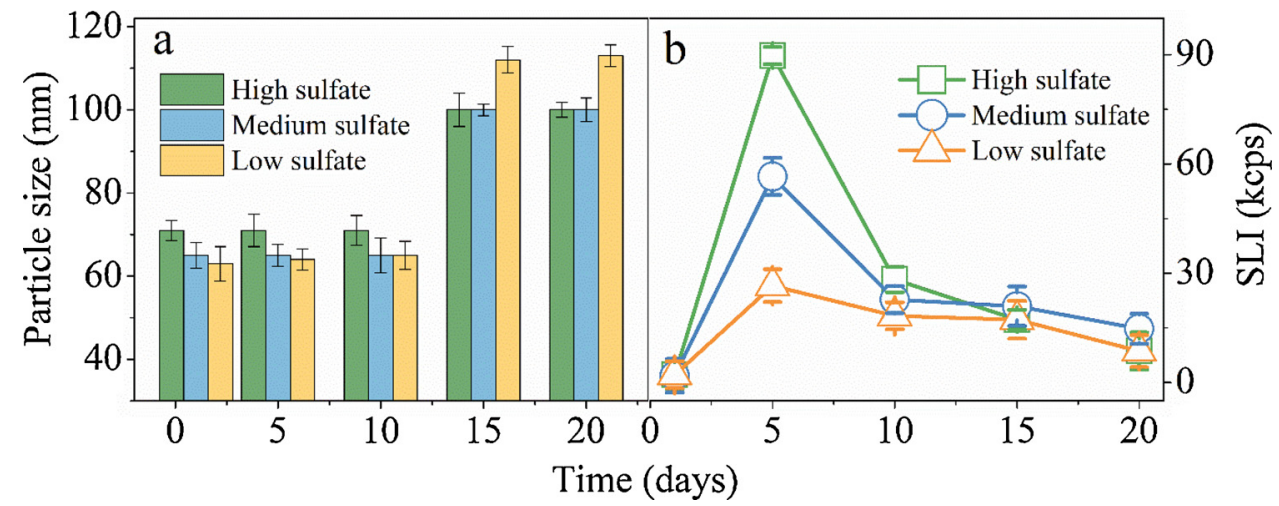

Fig. 4. Change in colloids particle size (a) and scattering light intensity (b) in the HS, MS, and LS treatment during soil flooding.
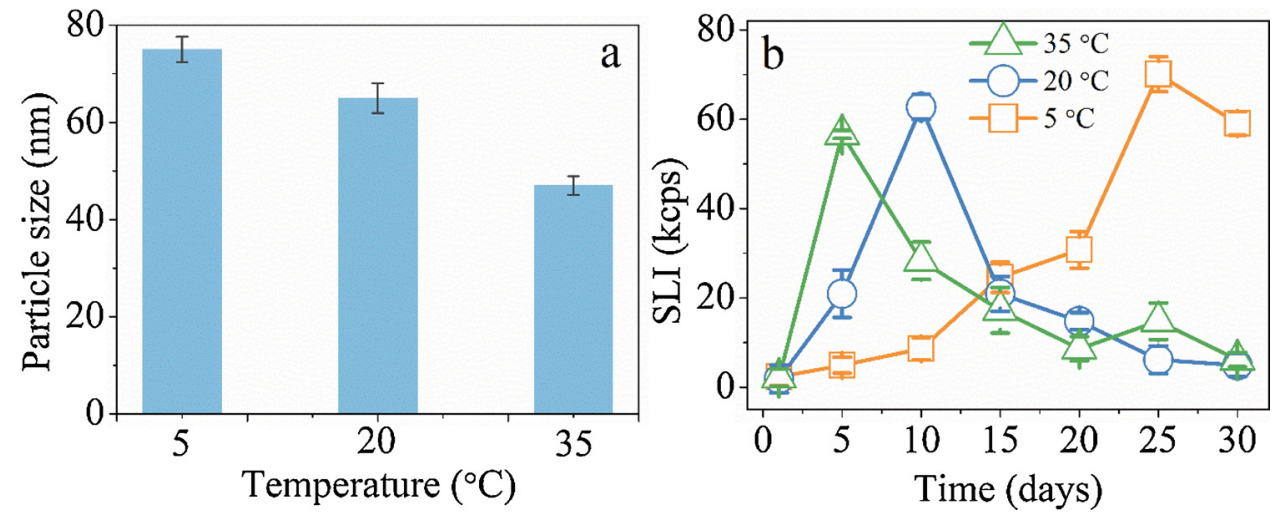

Fig. 5. Effect of temperature on colloids particle size (a) and scattering light intensity (b) during soil flooding.

a

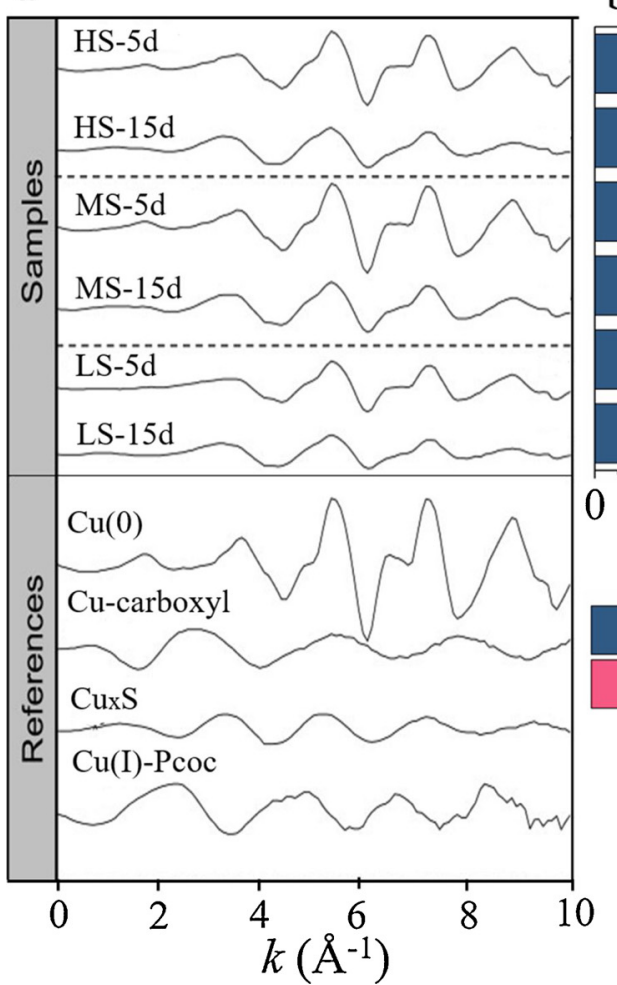

$\mathrm{b}$

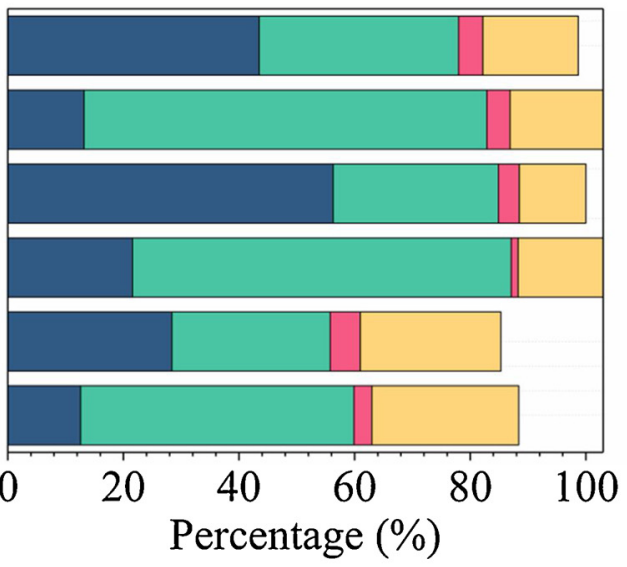

$\mathrm{Cu}(0)$ $\mathrm{Cu}(\mathrm{I})-\mathrm{Pcoc}$

Fig. 6. Colloidal Cu speciation during soil flooding with different initial sulfate concentration. (a) Normalized Cu EXAFS spectra of colloid and selected references. (b) Linear combination fitting results of colloid spectra. 
a

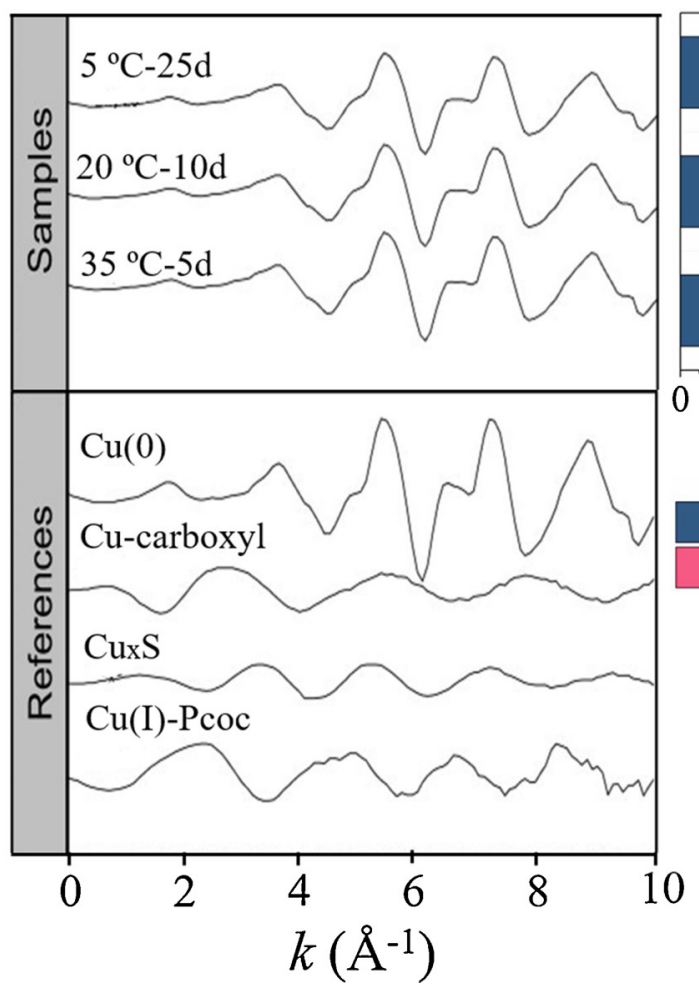

b

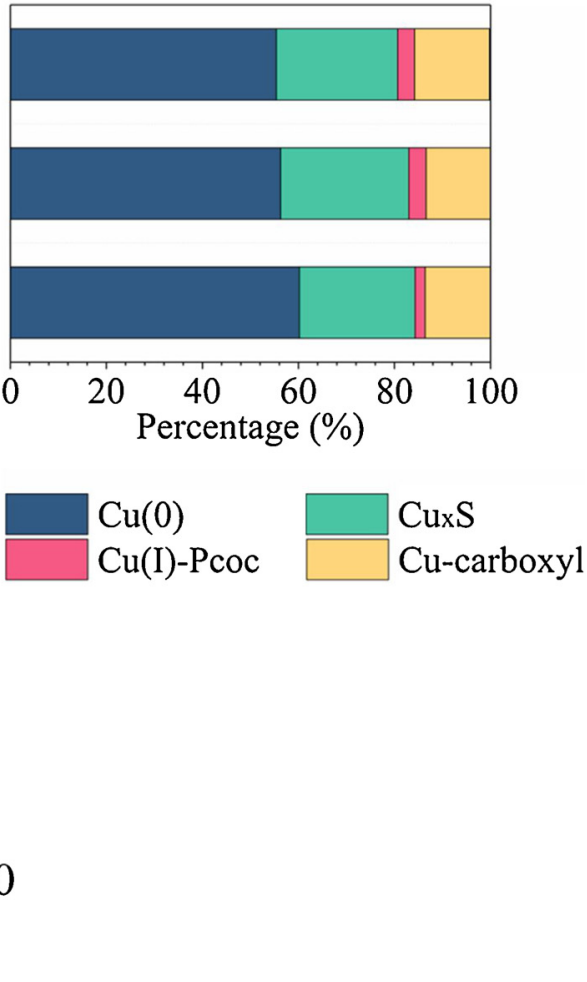

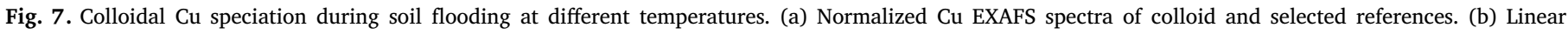
combination fitting results of colloid spectra.

in the case of medium (56.6 kcps) and low sulfate (26.6 kcps). This could be attributed to higher colloidal metal concentration in the high sulfate treatment.

Fig. 5 shows the particle size of the colloids and the light scattering intensity as affected by temperature. The average size of colloidal particles when the maximum release of colloids was $47 \mathrm{~nm}$ at $35^{\circ} \mathrm{C}, 65$ $\mathrm{nm}$ at $20{ }^{\circ} \mathrm{C}$, and $75 \mathrm{~nm}$ at $5{ }^{\circ} \mathrm{C}$, respectively. The PDI values of the colloidal samples were $0.180,0.251$, and 0.176 , respectively (Table S3). The trend of light scattering intensity was mainly consistent with the change of metal colloid concentration. However, compared with the treatments at $20^{\circ} \mathrm{C}$ and $35{ }^{\circ} \mathrm{C}$, the treatment at $5{ }^{\circ} \mathrm{C}$ showed higher peak value of light scattering intensity despite the lowest concentration of colloids, which could be attributed to the greater particle size. At lower temperature, lower microbial sulfate reduction not only results in lower oversaturation but also in more prolonged precipitation of metal colloids. Thus, slow growth and uniform agglomeration increased the size of metal colloids in the low temperature treatment (Banfield and Zhang, 2001). The decrease of temperature could also lead to a decline of ionic strength and the amount of natural organic ligands, which indirectly promoted the stability and growth of colloidal particles (Mullaugh and Luther, 2011). NOM exhibits a high affinity for heavy metals and plays important roles for stabilizing colloids. A previous study reported that colloidal metacinnabar-like species formed in DOM-containing sulfidic systems, and particle size increased with the increasing Hg: DOM ratio (Gerbig et al., 2011). The colloidal particles in the high temperature treatment might be more instability than in the low temperature as indicated by the sharply drop in the colloidal metal concentration. This phenomenon could be attributed to the easier aggregation and deposition at high temperature because high temperature could disrupt weak interaction forces and decrease electrostatic repulsion (Adeleye and Keller, 2014).

\subsection{Speciation of colloidal $\mathrm{Cu}$}

$\mathrm{Cu} \mathrm{K}$-edge X-ray absorption spectroscopy was applied to characterize the molecular level changes of colloidal $\mathrm{Cu}$ speciation during soil reduction. Fig. 6 and Table S4 show the normalized Cu EXAFS spectra of colloid and corresponding linear combination fitting results at high sulfate, medium sulfate, and low sulfate treatments. Samples at day 5 and day 15, which represented the highest and lowest value of colloidal $\mathrm{Cu}$ concentration, respectively, were selected to analyze the speciation change. $\mathrm{Cu}(0), \mathrm{Cu}_{\mathrm{x}} \mathrm{S}, \mathrm{Cu}(\mathrm{I})$-Pcoc, and $\mathrm{Cu}$-carboxyl were chosen as reference compounds.

After 5 days of incubation, $\mathrm{Cu}(0)$ was the most prominently colloidal species, accounting for $43.5 \%$ in HS, $56.3 \%$ in MS, and $28.4 \%$ in LS, respectively. Microbial reductive dissolution of Fe oxides occurred immediately at the beginning of flooding conditions. Such microbial anaerobic $\mathrm{Fe}$ respiration process could release $\mathrm{Cu}(\mathrm{II})$ ions into porewater that was previously bound to the Fe oxides. Then, $\mathrm{Cu}(\mathrm{II})$ was reduced to $\mathrm{Cu}(\mathrm{I})$ and $\mathrm{Cu}(0)$ through microbial metabolism, such as extracellular electron transfer or homeostasis-controlled $\mathrm{Cu}$ efflux mechanisms (Wakatsuki, 1995; Qiu et al., 2020). This process might result in the release of mobile $\mathrm{Cu}(0)$ colloids. For example, Manceau et al. (2008) reported that endomycorrhizal fungi assisted plants to transform $\mathrm{Cu}(\mathrm{II})$ ions into $\mathrm{Cu}(0)$ nanoparticles at the soil-root interface. In addition, $\mathrm{Cu}(\mathrm{I})$ disproportionation was another important pathway for producing $\mathrm{Cu}(0)$ species. Many biological and abiotic reduction mechanisms can lead to transformation of Cu(II) to Cu(I). Qiu et al. (2020) reported that Geobacter sulfurreducens could effectively reduce $\mathrm{Cu}$ (II) to $\mathrm{Cu}(\mathrm{I})$ in the presence of iron oxide nanoparticles that served as conduits and batteries to facilitate the electron transfer. Reduced soil humic acid resulted in the rapid reduction of $\mathrm{Cu}(\mathrm{II})$ to $\mathrm{Cu}(\mathrm{I})$ within $1 \mathrm{~h}$ under anoxic conditions (Maurer et al., 2013). Then, the unstable $\mathrm{Cu}(\mathrm{I})$ transformed into $\mathrm{Cu}(0)$ and $\mathrm{Cu}(\mathrm{II})$ through disproportionation.

$\mathrm{Cu}_{\mathrm{x}} \mathrm{S}$ was another important chemical species at day 5 , accounting 
for $34.5 \%$ in HS, $28.6 \%$ in MS, and $27.4 \%$ in LS, respectively. Reduced organic $\mathrm{S}$ groups may play vital roles in the formation of $\mathrm{Cu}_{\mathrm{x}} \mathrm{S}$ before the microbial sulfate reduction (Fulda et al., 2013a, c). After 15 days, microbial sulfate reduction was dominant. The $\mathrm{Cu}(0)$ colloids were then transformed to $\mathrm{Cu}_{\mathrm{x}} \mathrm{S}$ colloids via reaction with sulfide that produced by microbial sulfate reduction. In this case, the percentage of $\mathrm{Cu}(0)$ decreased by $55-70 \%$ and correspondingly $\mathrm{Cu}_{\mathrm{x}} \mathrm{S}$ increased by $42-60 \%$ in the sulfate treatments. The higher initial sulfate concentration resulted in a higher proportion of $\mathrm{Cu}_{\mathrm{x}} \mathrm{S}$ at day 15 . Therefore, it could be inferred that microbial sulfate reduction accelerated the transformation of metallic colloids. Weber et al. (2009a) found that homeostasis-controlled $\mathrm{Cu}(\mathrm{I})$ efflux mechanisms contributed to the formation of $\mathrm{Cu}(0)$ colloids, with $\mathrm{Cu}_{\mathrm{x}} \mathrm{S}$ species successively replacing $\mathrm{Cu}(0)$ crystal in flooded soil. The $\mathrm{Cu}_{\mathrm{x}} \mathrm{S}$ appeared as a hollow morphology associated with microbial cells. Such species transformation phenomenon could be affected by environment $\mathrm{pH}$. For example, the transformation of $\mathrm{Ag}$ nanoparticles to $\mathrm{Ag}_{2} \mathrm{~S}$ would be occurred theoretically at $\mathrm{pH}$ lower than 9.6. When $\mathrm{pH}$ lower than 9.6, sulfide species was mainly $\mathrm{H}_{2} \mathrm{~S}$ that could easily convert $\mathrm{Ag}(0)$ to $\mathrm{Ag}_{2} \mathrm{~S}$ (Liu et al., 2013).

A similar result was observed for the colloidal $\mathrm{Cu}$ speciation at the maximum release concentration of metal colloids during soil flooding in the different temperature treatments (Fig. 7 and Table S5). EXAFS spectra and $\mathrm{LCF}$ results indicated that $\mathrm{Cu}(0)$ was the dominating species in the $\mathrm{Cu}$ colloids at the highest metal colloids concentration, accounting for $55.4 \%$ at $5{ }^{\circ} \mathrm{C}, 56.3 \%$ at $20{ }^{\circ} \mathrm{C}$, and $60.2 \%$ at $35{ }^{\circ} \mathrm{C}$, respectively. $\mathrm{Cu}_{\mathrm{x}} \mathrm{S}$ and $\mathrm{Cu}$-carboxyl species also contributed significantly to the total amount of Cu colloids, whereas the remaining species were present in the $\mathrm{Cu}(\mathrm{I})-\mathrm{Pcoc}$ phase. However, the percentage of these four species showed no obvious difference between the three treatments at varying temperatures, indicating that low temperature only retarded the formation and transformation of $\mathrm{Cu}$ colloids but did not prevent these processes. The higher microbial activity and sulfate availability promoted and/or accelerated such release and transformation process of $\mathrm{Cu}$ colloids.

\section{Conclusions}

The present study revealed that reducible sulfate availability and temperature affected the formation and fate of $\mathrm{Cu}$ colloids thus controlling the metal dynamics and mobility in flooded paddy soils. The amount of sulfate limited the formation of sulfide during the flooding, reduced the release of metal colloids, and constrained the transformation of colloids into metal sulfide species. The metal sequestration was primarily consistent with the predicted thermodynamically sulfate ladder, which was reflected by the observation that $\mathrm{Cu}$ colloids were released prior to other chalcophile metals $(\mathrm{Cd}, \mathrm{Pb}, \mathrm{Zn})$. In the high sulfate availability, the presence of much more biogenic sulfide resulted in the faster deposition of $\mathrm{Cu}$ colloids with the ongoing of the microbial sulfate reduction, while under the low sulfate condition, lower oversaturation caused more uniform agglomeration and greater average particles sizes. Therefore, the amount of reducible sulfate influenced the release, transformation and deposition of $\mathrm{Cu}$ colloids and controlled the $\mathrm{Cu}$ solubility and mobility in flooded soils.

Our study also found that temperature affected the environmental behavior of $\mathrm{Cu}$ colloids by changing the microbial activity that is important for many biogeochemical reactions such as Fe and sulfate reduction. The higher temperature caused earlier and enhanced formation and precipitation of $\mathrm{Cu}$ colloids, which increased the mobilization of the metal contaminant over shorter periods of flooding time. In contrast, although lower temperature lowered the release of $\mathrm{Cu}$ colloids and also slowed down this release, the colloids were present obviously over the entire flooding period of 30 days. Thus, the risk of mobile $\mathrm{Cu}$ colloids during longer periods of time at low temperature should be further considered. Despite the temperature variation, the colloids could be still transformed from $\mathrm{Cu}(0)$ to $\mathrm{Cu}_{\mathrm{x}} \mathrm{S}$ species, indicating that low temperature only retarded the formation and transformation of colloids but did not prevent these processes. Overall, our results manifest that a series of factors need to be considered in the risk assessment of heavy metal contaminants in floodplain soils, such as soil chemical parameters, trace metals concentration, amount of biogenic sulfide, and environmental temperature.

\section{Author contribution statement}

$\mathrm{HQ}, \mathrm{BX}$, and $\mathrm{EH}$ conceived the idea and designed the experiment; $\mathrm{BX}$ and $\mathrm{HX}$ performed the experiment; $\mathrm{HX}, \mathrm{HQ}$, and $\mathrm{EH}$ wrote the manuscript; RQ, WP, LZ, XX, and XC revised the manuscript; HQ and $\mathrm{EH}$ raised the funding.

\section{Declaration of Competing Interest}

There is no competing interest to declare.

\section{Acknowledgements}

This study was sponsored by the National Key R\&D Program of China (No. 2018YFC1800600, No. 2018YFD0800700), the National Natural Science Foundation of China (No. 41877500, No. 41701571, No. 41701573, and No. 41977115), the Research Fund Program of Guangdong Provincial Key Laboratory of Environmental Pollution Control and Remediation Technology (No. 2018K01), and Shanghai Rising-Star Program (No. 20QA1404500).

\section{Appendix A. Supplementary data}

Supplementary material related to this article can be found, in the online version, at doi:https://doi.org/10.1016/j.jhazmat.2020.123462.

\section{References}

Adeleye, A.S., Keller, A.A., 2014. Long-term colloidal stability and metal leaching of single wall carbon nanotubes: effect of temperature and extracellular polymeric substances. Water Res. 49, 236-250. https://doi.org/10.1016/j.watres.2013.11.032.

Banfield, J.F., Zhang, H., 2001. Nanoparticles in the environment. Rev. Mineral. Geochem. 44, 1-58. https://doi.org/10.2138/rmg.2001.44.01.

Bradford, M.A., 2013. Thermal adaptation of decomposer communities in warming soils. Front. Microbiol. 4, 333. https://doi.org/10.3389/fmicb.2013.00333.

Brezonik, P.L., 1994. Chemical Kinetics and Process Dynamics in Aquatic Systems. CRC Press.

Chen, C., Li, L., Huang, K., Zhang, J., Xie, W.Y., Lu, Y., Dong, X., Zhao, F.J., 2019. Sulfatereducing bacteria and methanogens are involved in arsenic methylation and demethylation in paddy soils. ISME J. 13, 2523-2535. https://doi.org/10.1038/ s41396-019-0451-7.

Davranche, M., Bollinger, J.-C., 2000. Heavy metals desorption from synthesized and natural iron and manganese oxyhydroxides: effect of reductive conditions. J. Colloid Interface Sci. 227, 531-539. https://doi.org/10.1006/jcis.2000.6904.

Dijkstra, P., Dalder, J.J., Selmants, P.C., Hart, S.C., Koch, G.W., Schwartz, E., Hungate, B.A., 2011. Modeling soil metabolic processes using isotopologue pairs of positionspecific 13C-labeled glucose and pyruvate. Soil Biol. Biochem. 43, 1848-1857. https://doi.org/10.1016/j.soilbio.2011.05.001.

Fulda, B., Voegelin, A., Ehlert, K., Kretzschmar, R., 2013a. Redox transformation, solid phase speciation and solution dynamics of copper during soil reduction and reoxidation as affected by sulfate availability. Geochim. Cosmochim. Acta 123, 385-402. https://doi.org/10.1016/j.gca.2013.07.017.

Fulda, B., Voegelin, A., Maurer, F., Christl, I., Kretzschmar, R., 2013c. Copper redox transformation and complexation by reduced and oxidized soil humic acid. 1. X-ray absorption spectroscopy study. Environ. Sci. Technol. 47, 10903-10911. https://doi. org/10.1021/es4024089.

Gerbig, C.A., Kim, C.S., Stegemeier, J.P., Ryan, J.N., Aiken, G.R., 2011. Formation of nanocolloidal metacinnabar in mercury-DOM-sulfide systems. Environ. Sci. Technol. 45, 9180-9187. https://doi.org/10.1021/es201837h.

Grybos, M., Davranche, M., Gruau, G., Petitjean, P., 2007. Is trace metal release in wetland soils controlled by organic matter mobility or Fe-oxyhydroxides reduction? J. Colloid Interface Sci. 314, 490-501. https://doi.org/10.1016/j.jcis.2007.04.062.

Hagerty, S.B., Van Groenigen, K.J., Allison, S.D., Hungate, B.A., Schwartz, E., Koch, G.W., Kolka, R.K., Dijkstra, P., 2014. Accelerated microbial turnover but constant growth efficiency with warming in soil. Nat. Clim. Chang. 4, 903-906. https://doi.org/10. 1038/nclimate2361.

Hofacker, A.F., Voegelin, A., Kaegi, R., Kretzschmar, R., 2013a. Mercury mobilization in a flooded soil by incorporation into metallic copper and metal sulfide nanoparticles. Environ. Sci. Technol. 47, 7739-7746. https://doi.org/10.1021/es4010976. 
Hofacker, A.F., Voegelin, A., Kaegi, R., Weber, F.-A., Kretzschmar, R., 2013b. Temperature-dependent formation of metallic copper and metal sulfide nanoparticles during flooding of a contaminated soil. Geochim. Cosmochim. Acta 103, 316-332. https://doi.org/10.1016/j.gca.2012.10.053.

Huang, Y.Z., Luo, H.J., Yang, M., Dang, Z., 2010. Distribution and seasonal influence of manganese contamination in Dabaoshan Mine, Guangdong Province. Research of Environmental Sciences 23, 473-479.

Liao, P., Li, W.L., Jiang, Y., Wu, J.W., Yuan, S.H., Fortner, J.D., Giammar, D.E., 2017. Formation, aggregation, and deposition dynamics of NOM-Iron colloids at anoxicoxic interfaces. Environ. Sci. Technol. 51, 12235-12245. https://doi.org/10.1021/ acs.est.7b02356.

Liu, Z.H., Zhou, Y., Maszenan, A.M., Ng, W.J., Liu, Y., 2013. pH-dependent transformation of Ag nanoparticles in anaerobic processes. Environ. Sci. Technol. 47, 12630-12631. https://doi.org/10.1021/es404514g.

Ma, J.F., Yamaji, N., Mitani, N., Xu, X.Y., Su, Y.H., Mcgrath, S.P., Zhao, F.J., 2008. Transporters of arsenite in rice and their role in arsenic accumulation in rice grain. Proc. Natl. Acad. Sci. U.S.A. 105, 9931-9935. https://doi.org/10.1073/pnas. 0802361105.

Manceau, A., Nagy, K.L., Marcus, M.A., Lanson, M., Geoffroy, N., Jacquet, T., Kirpichtchikova, T., 2008. Formation of metallic copper nanoparticles at the soilroot interface. Environ. Sci. Technol. 42, 1766-1772. https://doi.org/10.1021/ es072017o.

Maurer, F., Christl, I., Fulda, B., Voegelin, A., Kretzschmar, R., 2013. Copper redox transformation and complexation by reduced and oxidized soil humic acid. 2 . Potentiometric titrations and dialysis cell experiments. Environ. Sci. Technol. 47, 10912-10921. https://doi.org/10.1021/es4024095.

Mullaugh, K.M., Luther, G.W., 2011. Growth kinetics and long-term stability of CdS nanoparticles in aqueous solution under ambient conditions. J. Nanopart. Res. 13, 393-404. https://doi.org/10.1007/s11051-010-0045-9.

Pattrick, Ra.D., Mosselmans, J.F.W., Charnock, J.M., England, K.E.R., Helz, G.R., Garner, C.D., Vaughan, D.J., 1997. The structure of amorphous copper sulfide precipitates: an X-ray absorption study. Geochim. Cosmochim. Acta 61, 2023-2036. https://doi.org/ 10.1016/S0016-7037(97)00061-6.

Peariso, K., Huffman, D.L., Penner-Hahn, J.E., O'halloran, T.V., 2003. The PcoC copper resistance protein coordinates $\mathrm{Cu}(\mathrm{I})$ via novel S-Methionine interactions. J. Am. Chem. Soc. 125, 342-343. https://doi.org/10.1021/ja028935y.

Qiu, H., Xu, H., Xu, Z., Xia, B., Peijnenburg, W.J.G.M., Cao, X., Du, H., Zhao, L., Qiu, R., He, E., 2020. The shuttling effects and associated mechanisms of different types of iron oxide nanoparticles for $\mathrm{Cu}(\mathrm{II})$ reduction by Geobacter sulfurreducens. J. Hazard. Mater. 393, 122390. https://doi.org/10.1016/j.jhazmat.2020.122390.
Rousk, J., Frey, S.D., Baath, E., 2012. Temperature adaptation of bacterial communities in experimentally warmed forest soils. Glob. Change Biol. Bioenergy 18, 3252-3258. https://doi.org/10.1111/j.1365-2486.2012.02764.x.

Sinsabaugh, R.L., Turner, B.L., Talbot, J.M., Waring, B.G., Powers, J.S., Kuske, C.R., Moorhead, D.L., Shah, J.J.F., 2016. Stoichiometry of microbial carbon use efficiency in soils. Ecol. Monogr. 86, 172-189. https://doi.org/10.1890/15-2110.1.

Van Bodegom, P., Stams, A., 1999. Effects of alternative electron acceptors and temperature on methanogenesis in rice paddy soils. Chemosphere 39, 167-182. https:// doi.org/10.1016/s0045-6535(99)00101-0.

Wagner, S., Gondikas, A., Neubauer, E., Hofmann, T., Von Der Kammer, F., 2014. Spot the difference: engineered and natural nanoparticles in the environment-release, behavior, and fate. Angew. Chem. Int. Ed. Engl. 53, 12398-12419. https://doi.org/10. 1002/anie.201405050.

Wakatsuki, T., 1995. Metal oxidoreduction by microbial cells. J. Ind. Microbiol. 14, 169-177. https://doi.org/10.1007/BF01569900.

Wang, Y., Frutschi, M., Suvorova, E., Phrommavanh, V., Descostes, M., Osman, A.A., Geipel, G., Bernier-Latmani, R., 2013. Mobile uranium(IV)-bearing colloids in a mining-impacted wetland. Nat. Commun. 4, 2942. https://doi.org/10.1038/ ncomms3942.

Wang, J., Wang, P.M., Gu, Y., Kopittke, P.M., Zhao, F.J., Wang, P., 2019. Iron-manganese (oxyhydro)oxides, rather than oxidation of sulfides, determine mobilization of $\mathrm{Cd}$ during soil drainage in paddy soil systems. Environ. Sci. Technol. 53, 2500-2508. https://doi.org/10.1021/acs.est.8b06863.

Weber, F.-A., Voegelin, A., Kaegi, R., Kretzschmar, R., 2009a. Contaminant mobilization by metallic copper and metal sulphide colloids in flooded soil. Nat. Geosci. 2, 267-271. https://doi.org/10.1038/ngeo476.

Weber, F.-A., Voegelin, A., Kretzschmar, R., 2009b. Multi-metal contaminant dynamics in temporarily flooded soil under sulfate limitation. Geochim. Cosmochim. Acta 73, 5513-5527. https://doi.org/10.1016/j.gca.2009.06.011.

Won, J., Burns, S.E., 2018. Role of immobile kaolinite colloids in the transport of heavy metals. Environ. Sci. Technol. 52, 2735-2741. https://doi.org/10.1021/acs.est. $7 \mathrm{~b} 05631$.

Xia, B., Qiu, H., Knorr, K.-H., Blodau, C., Qiu, R., 2018. Occurrence and fate of colloids and colloid-associated metals in a mining-impacted agricultural soil upon prolonged flooding. J. Hazard. Mater. 348, 56-66. https://doi.org/10.1016/j.jhazmat.2018.01. 026.

Xu, H., Xu, M., Li, Y., Liu, X., Guo, L., Jiang, H., 2018. Characterization, origin and aggregation behavior of colloids in eutrophic shallow lake. Water Res. 142, 176-186. https://doi.org/10.1016/j.watres.2018.05.059. 